\title{
Electrotonic Characteristics of the Rodent Dorsal Raphe Neurons
}

\author{
HIROSHI UCHIYAMA, HIDEHO HIGASHI AND SYOGORO NISHI \\ Department of Physiology, Kurume University School of Medicine, Kurume, 830 \\ and Chikusuikai Institute for Neuroinformation, Yame, 834 Japan
}

Received for publication December 18, 1982

\begin{abstract}
Key words: dorsal raphe neurons - electrotonic parameters - membrane constants - dendritic-to-soma conductance ratio - electrotonic length of dendrites
\end{abstract}

The raphe nucleus, particularly its dorsal region densely contains serotonergic neurons which project their axons to various parts of the brain (Dahlström and Fuxe, 1964; Palkovits et al. 1974). Although much investigation has been conducted on the physiological function of this nucleus, the passive electrical property of its constituent neurons has not been explored except for a recent experiment by Aghajanian and Vandermaelen (1982). The present study aimed at the intracellular recording of the dorsal raphe nucleus (DRN) neurons in an in vitro condition to obtain the basic electrotonic characteristics and membrane constants of these neurons.

Adult male Wistar rats weighing 150 to $250 \mathrm{~g}$ were killed by a heavy blow to the thorax. The brain was rapidly removed, the pia stripped, and a block of midbrain tissue containing the raphe nucleus was mounted on a slicing deck with cyanoacry lic glue with the rostral surface uppermost. Sections of about $300 \mu \mathrm{m}$ thickness were cut from this block with an Oxford vibratome at $4-6{ }^{\circ} \mathrm{C}$. A section containing the DRN was placed on a nylon net in a small recording chamber (volume of $1 \mathrm{ml}$ ) and prevented from floating by a titanium grid resting on its upper surface. The tissue was submerged in a Krebs solution of the following composition (mM): $\mathrm{NaCl} 117.0$, $\mathrm{KCl}$ 4. 7, $\mathrm{CaCl}_{2} 2.5, \mathrm{MgCl}_{2} 1.2, \mathrm{NaH}_{2} \mathrm{PO}_{4}$ 1.2, $\mathrm{NaHCO}_{3} 25.0$, glucose 11.5 (saturated with $95 \% \mathrm{O}_{2}-5 \% \mathrm{CO}_{2}$, pH 7.4). The solution was heated prior to flowing through the chamber at a rate of $2 \mathrm{ml} / \mathrm{min}$ adjusted by a peristaltic pump, so that the temperature at the recording site was $35^{\circ} \mathrm{C}$.

The position of the DRN could be easily identified in the living slice by reference to the aqueductus cerebri (Sylvii), the substantia grisea centralis, the fasciculus longitudinalis medialis and the pedunculus cerebellaris superior.

Intracellular recordings were made using glass microelectrodes containing $\mathrm{KCl}(3 \mathrm{M})$ with DC resistances of $60-100 \mathrm{M} \Omega$. Potentials were amplified and recorded by conventional techniques, using a preamplifier with facility for current injection.

Electrotonic characteristics of DRN neurons were obtained by the "peeling" method (Lux and Pollen, 1966; Burke and ten Bruggencate, 1971; Brown et al. 1981). The "peeling" of semilogarithmic plots of $\mathrm{dv} / \mathrm{dt}$ versus $\mathrm{t}$ from the charging transients of a neuron reveals the values of the membrane time constant $\left(\tau_{0}\right)$ and its coefficient $\left(\mathrm{C}_{0}\right)$, as well as $\mathrm{C}_{\mathrm{n}}$ and $\tau_{\mathrm{n}}$. The dendriticto-soma conductance ratio $(\rho)$ and the electrotonic length of the dendrites ( $L$; the 


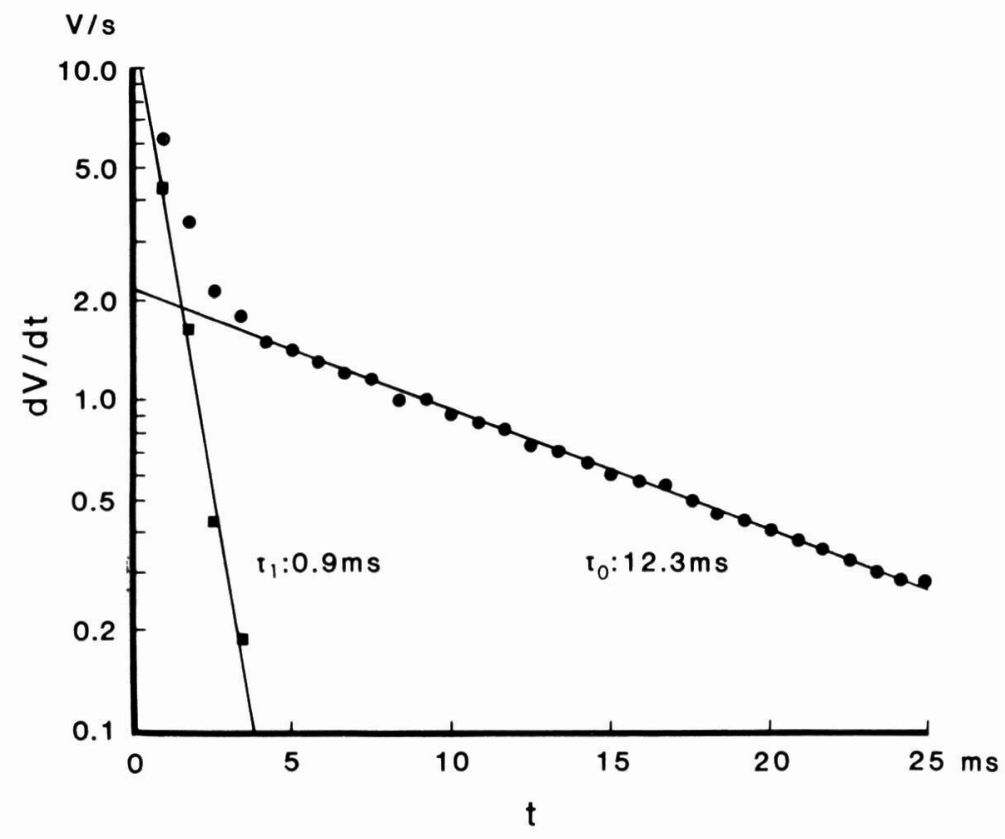

Fig. 1. Log dv/dt (ordinate) of a hyperpolarizing electrotonic potential measured every $0.83 \mathrm{msec}$ was plotted (circles) against the time (t) after the onset of the current applied (abscissa). The slow time constant $\left(\tau_{0}\right)$ of the slope of the charging curve is the membrane time constant. The value of this exponential function at each time $(t)$ was subtracted from the corresponding data points at shorter times and the difference was replotted (squares). The time constant of this fast exponential slope corresponds to the first equalizing time constant $\left(\boldsymbol{\tau}_{1}\right)$. In general, $\boldsymbol{\tau}$ components beyond $\tau_{1}$ could not be extracted from the charging transients of DRN neurons.

TABLE 1

Electrotonic and membrane constants of DRN neurons

\begin{tabular}{clc}
\hline \multicolumn{2}{c}{ constants } & mean \pm S. E. ${ }^{*}$ \\
\hline $\mathrm{R}_{\mathrm{m}}$ & $\left(\Omega \cdot \mathrm{cm}^{2}\right)$ & $7057 \pm 337$ \\
$\tau_{0} \quad(\mathrm{msec})$ & $13.8 \pm 9.3$ \\
$\tau_{1}$ & $(\mathrm{msec})$ & $1.4 \pm 0.9$ \\
$\mathrm{C}_{\mathrm{m}}$ & $\left(\mu \mathrm{F} / \mathrm{cm}^{2}\right)$ & $2.1 \pm 1.4$ \\
$\rho$ & & $4.3 \pm 1.7$ \\
$\mathrm{~L}$ & & $0.86 \pm 0.15$
\end{tabular}

* Values were obtained from 20 neurons. 
ratio of the length to the space constant of the dendrites) can be estimated without obtaining geometric parameters by the following equations (Brown et al. 1981):

$$
\begin{aligned}
& \rho=\left(\mathrm{G}_{\mathrm{N}} \tau_{0} / \mathrm{I}\right) \sum_{\mathrm{i}=0}^{\infty}\left(\mathrm{C}_{\mathrm{i}} / \tau_{\mathrm{i}}\right)-1 \\
& \mathrm{~L} \simeq \pi\left(\frac{\rho /(\rho+1)}{\tau_{0} / \tau_{1}-1}\right)^{1 / 2}
\end{aligned}
$$

The soma conductance $\left(\mathrm{G}_{\mathrm{s}}\right)$ and the membrane resistance $\left(R_{m}\right)$ and capacitance $\left(\mathrm{C}_{\mathrm{m}}\right)$ for a unit area can be obtained by the following relationships, respectively: $\mathrm{G}_{\mathrm{s}}=\mathrm{G}_{\mathrm{N}} / \rho+1, \mathrm{R}_{\mathrm{m}}=\tau_{0} / \mathrm{C}_{\mathrm{m}}$ and $\mathrm{C}_{\mathrm{m}}=\tau_{0} \mathrm{G}_{\mathrm{s}} /$ $A_{S} . G_{N}$ is the total neuron resistance, and $A_{S}$ the surface area of the soma. The $A_{S}$ value was assumed to be $1030 \mu \mathrm{m}^{2}$, based on our measurement of $20 \mathrm{DRN}$ neurons intracellularly stained with horseradish peroxidase (Uchiyama, Higashi and Nishi, unpublished observations).

It was considerably difficult to obtain long and steady intracellular recordings from DRN neurons. This would be mainly due to the smallness $(10-20 \mu \mathrm{m}$ in diameter) of DRN neurons. A momental microvibration of the electrode tip brought about the most successful impalement of the neurons. In practice, a ziffy oscillation was induced by an over compensation of the input capacitance after each 10 - to $20-\mu \mathrm{m}$ advancement of the electrode tip in the slice. A steady intracellular recording lasting over $30 \mathrm{~min}$ could be made in only about $10 \%$ of the neurons which showed sufficient resting and action potentials at the time of impalement.

The resting potential of DRN neurons ranged between -40 and $-60 \mathrm{mV}$, and their input resistance varied from 50 to $400 \mathrm{M} \Omega$. Most neurons showed a linear I-V relationship within 30 to $50 \mathrm{mV}$ of hyperpolarization, but beyond such levels their chord conductance tended to decrease to some extent. On the depolarizing side of the resting potential there was a noticeable $(30-40 \%)$ rectification to subliminal current pulses.
The hyperpolarizing electrotonic potentials with a final amplitude of 10 to $15 \mathrm{mV}$ and a duration of 70 to $150 \mathrm{msec}$ were subjected to the present analysis. The dv/ $\mathrm{dt}$ of the anodal charging transients was measured at a short interval (usually every $0.83 \mathrm{msec}$ ) and plotted semilogarithmically against the time after the initiation of current application (Fig. 1). The graphical analysis revealed two different time constants $\tau_{0}$ and $\tau_{1}$ which were, respectively, some ten milliseconds and about $1.5 \mathrm{msec}$. The actual values of $\tau_{0}$ and $\tau_{1}$ and those of $\mathrm{R}_{\mathrm{m}}, \mathrm{C}_{\mathrm{m}}, \rho$ and $\mathrm{L}$ are shown in Table 1 .

As seen in the table, the dendritic-tosoma conductance ratio $(\rho)$ for DRN neurons is approximately 4 . This is about one half of the $\rho$ value for motoneurons (see Rall, 1977). Apparently, the fraction of a steady soma current spreading into the dendrites is about twice smaller in DRN neurons as compared to motoneurons. The electrotonic length of the DRN neuron dendrites (L) was only 0.86 , indicating that the actual length of the dendrites is slightly shorter than their length constant $(\lambda)$. In a uniform cylinder of electrotonic length $\mathrm{L}$, the steady state voltage attenuation factor $(\mathrm{H})$ is given by $\mathrm{H}=\cosh \mathrm{L}$ (Jack et al. 1975). The $\mathrm{L}$ value of 0.86 yields the attenuation factor $(\mathrm{H})$ of 1.39 . This $H$ value implies that the voltage reduction over the length of the cable is only $28 \%$. It appears therefore that the synaptic and intrinsically active potentials in the DRN neuron dendrites quite effectively spread to the soma, except, of course, their fast components that leak through the membrane capacitances.

The result shows that DRN neurons are compact in electrotonic structure and that their passive membrane constants are similar to those of autonomic ganglion cells (Nishi and Christ, 1971; Nishi, 1974).

This study was supported in part by a Grant-in-Aid for Scientific Research from the Ministry of Education, Science and Culture of Japan. 


\section{References}

Aghajanian, G. K. and Vandermaelen, C. P. (1982). Intracellular recordings from serotonergic dorsal raphe neurons: pacemaker potentials and the effect of LSD. Brain Res. 238, 463-469.

Brown, T. H., Perkel, D. H., Norris, J. C. and PEACOCK, J.H. (1981). Electrotonic structure and specific membrane properties of mouse dorsal root ganglion neurons. J. Neurophysiol. 45, 1-15.

Burke, R. E. and ten Bruggencate, G. (1971). Elecrotonic characteristics of alpha motoneurones of varying size. J. Physiol. (Lond.) 212, 1-20.

Dahlström, A. and Fuxe, K. (1964). Evidence for the existence of monoamine-containing neurons in the central nervous system. I. Demonstration of monoamines in the cell bodies of brain stem neurons. Acta Physiol. Scand. 62, Suppl. 232, 1-55.

Jack, J. J. B., Noble, D. and TSIen, R. W. (1975). Electric Current Flow in Excitable Cells. Clarendon, Oxford.
Lux, H.D. and Pleen, D. A. (1966). Electrical constants of neurons in the motor cortex of the cat. J. Neurophysiol. 29, 207-220.

Nishi, S. (1974). Ganglionic Transmission. In "The Peripheral Nervous System". Ed. by Hubberd J. I., p 225-255, Plenum Press, New York.

Nishi, S. and Christ, D. D. (1971). Electrophysiological and anatomical properties of mammalian parasympathetic ganglion cells. Proc. Internat. Union Physiol. Sci. IX, 421.

Palkovits, M., Brownstein, M. and SaAvedra, J.M. (1974). Serotonin content of the brain stem nuclei in the rat. Brain Res. 80, 237249.

RALL, W. (1959). Branching dendritic trees and motoneuron membrane resistivity. Exp. Neurol. 1, 491-527.

Rall, W. (1977). Core conductor theory and cable properties of neurons. In "Handbook of Physiology, Section 1: The Nervous System, Volume I . Cellular Biology of Neurons, Part 1". Ed. by Kandel, E. R., p 39-97, American Physiological Society, Bethesda, Maryland. 